\title{
Physiological and Psychological Effects on High School Students of Viewing Real and Artificial Pansies
}

\author{
Miho Igarashi ${ }^{1}$, Mariko Aga ${ }^{1}$, Harumi Ikei ${ }^{1}$, Takafumi Namekawa ${ }^{2}$ and Yoshifumi Miyazaki ${ }^{1, *}$ \\ 1 Center for Environment, Health and Field Sciences, Chiba University, 6-2-1 Kashiwa-no-ha, \\ Kashiwa, Chiba 277-0882, Japan; E-Mails: miho.murachi@gmail.com (M.I.); \\ marikoaga@gmail.com (M.A.); ikei.harumi@gmail.com (H.I.) \\ 2 Chiba Prefectural Kashiwanoha Senior High School, 6-1 Kashiwa-no-ha, Kashiwa, \\ Chiba 277-0882, Japan; E-Mail: tname2@gmail.com \\ * Author to whom correspondence should be addressed; E-Mail: ymiyazaki@faculty.chiba-u.jp; \\ Tel.: +81-4-7137-8113; Fax: +81-4-7137-8008.
}

Academic Editor: Paul B. Tchounwou

Received: 26 January 2015 / Accepted: 17 February 2015 / Published: 25 February 2015

\begin{abstract}
The relaxation effects of gardening have attracted attention; however, very few studies have researched its physiological effects on humans. This study aimed to clarify the physiological and psychological effects on high school students of viewing real and artificial pansies. Forty high school students (male: 19, female: 21) at Chiba Prefectural Kashiwanoha Senior High School, Japan, participated in this experiment. The subjects were presented with a visual stimulation of fresh yellow pansies (Viola $x$ wittrockiana "Nature Clear Lemon") in a planter for $3 \mathrm{~min}$. Artificial yellow pansies in a planter were used as the control. Heart rate variability was used as a physiological measurement and the modified semantic differential method was used for subjective evaluation. Compared with artificial pansies, visual stimulation with real flowers resulted in a significant decrease in the ratio of low- to high-frequency heart rate variability component, which reflects sympathetic nerve activity. In contrast, high frequency, which reflects parasympathetic nerve activity, showed no significant difference. With regard to the psychological indices, viewing real flowers resulted in "comfortable", "relaxed", and "natural" feelings. The findings indicate that visual stimulation with real pansies induced physiological and psychological relaxation effects in high school students.
\end{abstract}


Keywords: flowers; artificial flowers; horticultural therapy; high school students; stress reduction; heart rate variability

\section{Introduction}

In the increasingly urbanized and technological modern society, mitigation of stress is a great concern and much attention has been paid to the relaxation effects of the natural environment. Humans emerged millions of years ago [1,2] and evolved while adapting to natural environments; therefore, human stress states are believed to be mitigated by contact with natural environments [3-5]. Miyazaki et al. (2011) mentioned that humans who live in modern society have experienced more than $99.9 \%$ of the evolutionary process in natural environments [4]. Our bodies, which are adjusted to natural environments, cannot respond well to the suddenly developed artificial society; thus, we always feel stressed. For example, an epidemiological investigation that focused on a green tract of land showed that the area had low mortality of residents [6]. Another study pointed out the importance of a green tract of land in urban residential environments [7].

In cities, gardening enables easy contact with natural environments and has received considerable attention [8]. School and community gardens are used for improving stress states and for rehabilitation in hospitals or welfare facilities [9]. However, studies on the effects of gardening on humans have been limited to psychological indices such as questionnaires; very rarely have studies reported on the physiological evaluation of the effects of gardening. Some psychological evaluations have reported the use of gardening in rehabilitation, e.g., in older people ([10-16], patients with clinical depression [17,18], those with substance abuse [19], patients in an inpatient cardiopulmonary rehabilitation program [20], and patients with brain damage [21]. Some reports have also indicated the health benefits of community gardens [22-24] and schoolyards [25]. However, few studies have measured the physiological effects of gardening. Van den Berg and Custers (2011) reported that salivary cortisol levels are decreased by gardening activity [26]. However, they used indoor reading as a control, which may compromise broad interpretation of the results. A study of fresh chrysanthemum transplantation [27] revealed no significant differences among subjects; however, the authors indicated significant differences according to personality classifications, which we believe was a limitation.

We have studied the effects of nature-derived stimulation, such as that of a forest [28-36], parks [37,38], a rooftop garden [39], flowers [40-42], foliage plants [43,44], and olfactory stimulation [45-49]. We observed that these natural environments and plants have physiological relaxation effects and can reduce stress states. In this study, using heart rate variability (HRV) by fingertip acceleration pulse wave, we elucidated the physiological effects of visual stimulation with flowers in a gardening activity.

We focused on the stress state of minors (high school students) and studied the physiological effects of viewing flowers in a gardening activity. Some reports have stated that the numbers of high school students with stress and uneasiness have increased in Japan [50], the United States [51], and England [52]. 
Therefore, to clarify the physiological effects of visual stimulation with pansies, which are the most wholesale variety of flower beds, we recruited Japanese high school students and recorded their HRV using fingertip acceleration pulse wave.

\section{Experimental Section}

We conducted this study in Chiba Prefectural Kashiwanoha Senior High School on October 30 and November 1, 2, and 5, 2012. The average temperature, humidity, and intensity of illumination in a classroom were $22.5{ }^{\circ} \mathrm{C} \pm 1.1{ }^{\circ} \mathrm{C}, 50.9 \% \pm 5.3 \%$, and $1030 \mathrm{~lx}$, respectively. The participants were 19 healthy high school boys (mean age \pm standard deviation: $16.2 \pm 0.7$ years) and 21 healthy high school girls (mean age \pm standard deviation: $16.6 \pm 0.9$ years).

All subjects agreed to the study protocol and provided written informed consent. The study was conducted according to the regulations of the Ethics Committee of the Center for Environment, Health, and Field Sciences, Chiba University, Japan.

Figure 1 shows the experimental design. After listening to the details of the experiment in a classroom different from the experimental room, the subjects practiced subjective evaluation. Then, they moved into the experimental room and formed pairs. In a seated position, the subjects rested for $1 \mathrm{~min}$ in front of a cardboard box covering pansies in a planter. The subjects then received visual stimulation with either real pansies (hereafter real flowers) (Figure 1, left) or artificial pansies (hereafter artificial flowers) (Figure 1, right) for $3 \mathrm{~min}$. We measured fingertip accelerated plethysmography and pulse rate continually during the experiment. After visual stimulation, subjective evaluation was performed. The student pairs took turns in the visual stimulation, providing counterbalance between subjects.
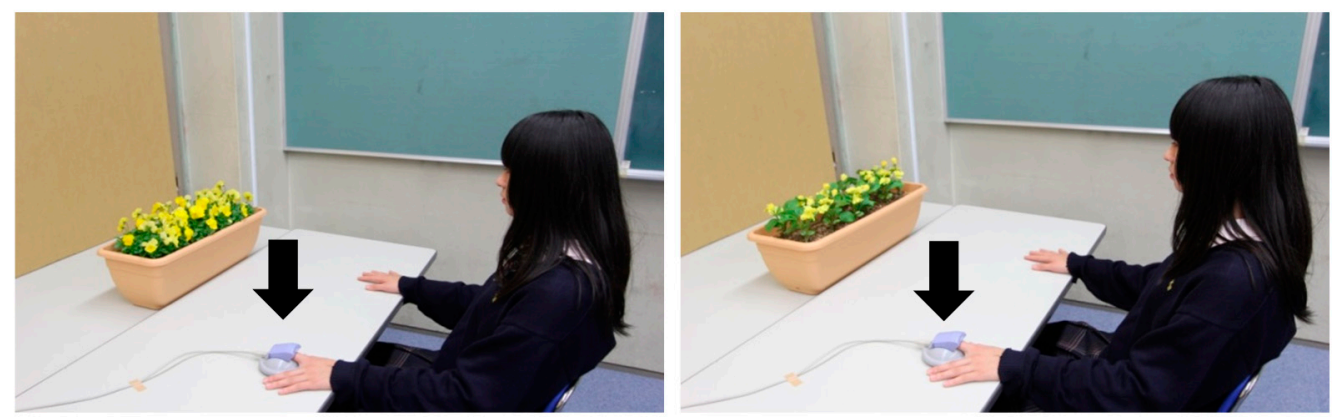

Figure 1. Visual stimulation with real flowers (left) and artificial flowers (right). The black arrow indicates the accelerated plethysmograph (ARTETT; U-medica, Inc., Co.).

For visual stimulation, we used fresh yellow pansies (Viola $x$ wittrockiana, "Nature Clear Lemon"). The pansies' scent was evaluated as "weak" in terms of the sense of strength and "slightly good" in the sensuality evaluation by the modified semantic differential (SD) method. The artificial flowers were yellow pansies made of polyester. Twelve real and 12 artificial flowering plants were set with gardening soil in a polypropylene planter (55 cm long, $21.5 \mathrm{~cm}$ wide, $18 \mathrm{~cm}$ high).

As a physiological measurement, HRV was calculated by spectral analysis of the coefficient of variation of the a-a interval on an accelerated plethysmograph (ARTETT, U-Medica Inc., Osaka, Japan) 
[53], and the pulse rates were converted by a 60/a-a interval. The sampling frequency was $1000 \mathrm{~Hz}$. The power levels of the high-frequency (HF) $(0.15-0.40 \mathrm{~Hz})$ and low-frequency (LF) $(0.04-0.15 \mathrm{~Hz}) \mathrm{HRV}$ components were calculated by the maximum entropy method (MemCalc/Win; GMS) [54]. The HF power was considered to reflect parasympathetic nerve activity, and the LF/HF power ratio was determined to reflect sympathetic nerve activity $[55,56]$. The subjects placed their left forefingers on the sensor of an accelerated plethysmograph and measurements were performed continuously for 3 min during visual stimulation. Concerning HRV and pulse rate measurement by plethysmography, we calculated time-dependent changes every minute with a mean of 3 min.

Evaluation by the modified SD method [57] was performed using 3 pairs of adjectives on 13 scales, including "comfortable-uncomfortable", "relaxed-awakening", and "natural-artificial".

Statistical analysis was performed using SPSS 20.0 (IBM Corp., Armonk, NY, USA). A paired $t$ test compared the differences in the mean physiological data, and a value of $p<0.05$ was considered to indicate statistical significance. The Wilcoxon signed-rank test was used to analyze differences in the psychological indices, and values of $p<0.01$ were considered to indicate statistical significance. A one-sided test was used in this study because of the hypothesis that humans would be relaxed by viewing real flowers.

\section{Results}

Time-dependent LF/HF, which reflects sympathetic nerve activity, changed every minute during visual stimulation with real flowers or control, as shown in Figure 2a. Visual stimulation with real flowers showed lower values than that with artificial flowers ( $0-1$ min, real flowers: $1.66 \pm 0.23$, artificial flowers: $1.84 \pm 0.29 ; 1-2 \mathrm{~min}$, real flowers: $1.45 \pm 0.23$, artificial flowers: $1.61 \pm 0.24$; and 2-3 min, real flowers: $1.48 \pm 0.24$, artificial flowers: $1.71 \pm 0.25$ ). Real flowers showed lower movement than artificial flowers: at 0-1 min, 9.6\% lower; 1-2 min, 9.6\% lower; 2-3 min, 13.4\% lower. The mean $\mathrm{LF} / \mathrm{HF}$ value for $3 \mathrm{~min}$ is shown in Figure $2 \mathrm{~b}$. The value for real flowers was $1.42 \pm 0.17$, whereas that for artificial flowers was $1.64 \pm 0.22$; hence, real flowers showed a significant decrease of $13.8 \%(p<0.05)$. The pre-value for real flowers and artificial flowers was $1.29 \pm 0.19$ and $1.23 \pm 0.18$, respectively, indicating no significant difference. In contrast, HF (which is considered to reflect parasympathetic nerve activity) and pulse rate did not show a significant difference.

A modified SD method was used for subjective evaluation of "comfortable", "relaxed", and "natural" feelings (Figure 3). Subjective evaluation of "comfortable" indicated that subjects felt "slightly comfortable" with real flowers. The difference between real flowers and artificial flowers was statistically significant $(p<0.01)$, with the subjects feeling more comfortable with real flowers than with artificial flowers. In terms of "relaxed" feeling, the subjects felt "slightly relaxed" by real flowers. The difference between real flowers and artificial flowers was statistically significant $(p<0.01)$, with the subjects feeling more relaxed with real flowers than with artificial flowers. In terms of "natural" feeling, the subjects felt "slightly natural" to "moderately natural" with real flowers. In this respect, the difference between real flowers and artificial flowers was statistically significant $(p<0.01)$, with the subjects feeling "more natural" with real flowers than with artificial flowers. 
(a)

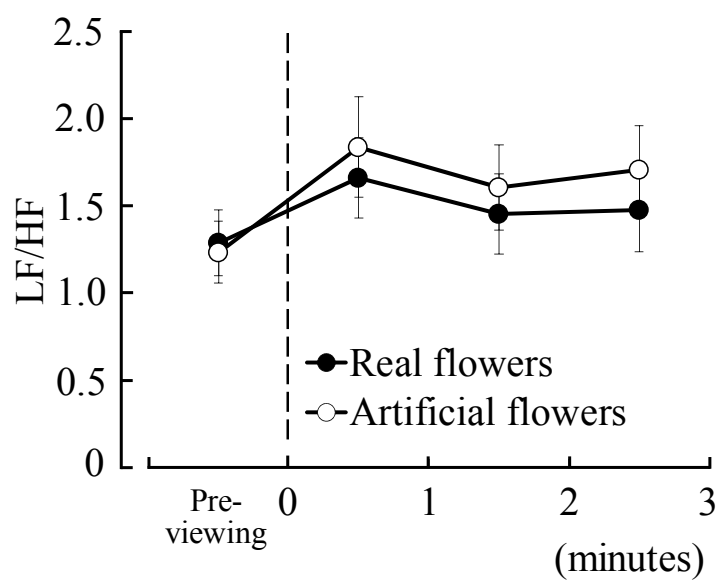

(b)

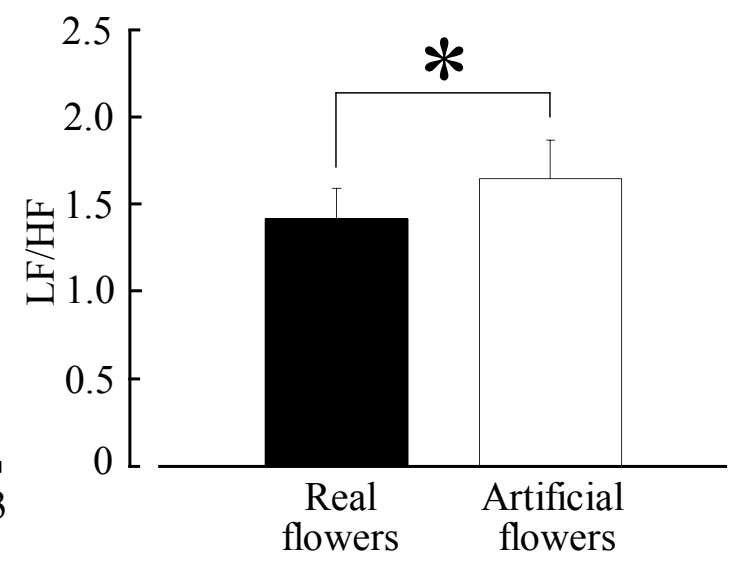

Figure 2. (a) Change in the low-frequency (LF)/high-frequency (HF) values of heart rate variability (HRV) between real and artificial flowers; (b) Comparison of LF/HF values of HRV between real and artificial flowers. $n=40$, mean \pm SE. $* p<0.05$, determined by paired $t$-test (one-sided).

Real flowers $\square$ Artificial flowers

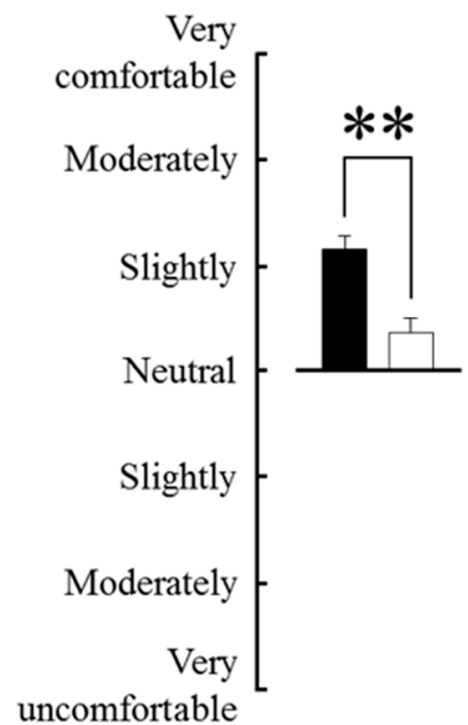

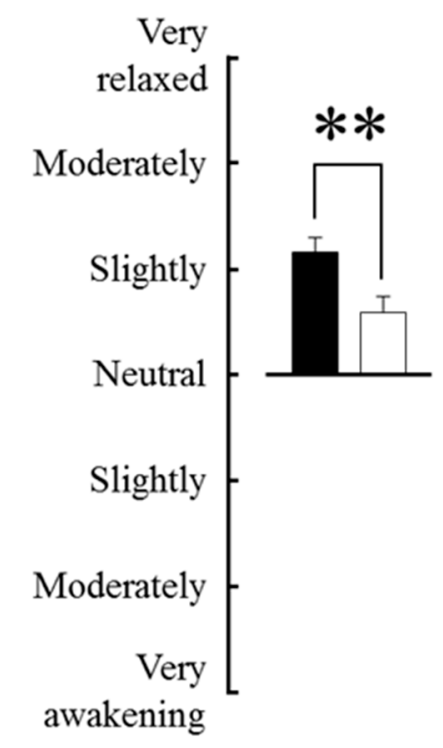

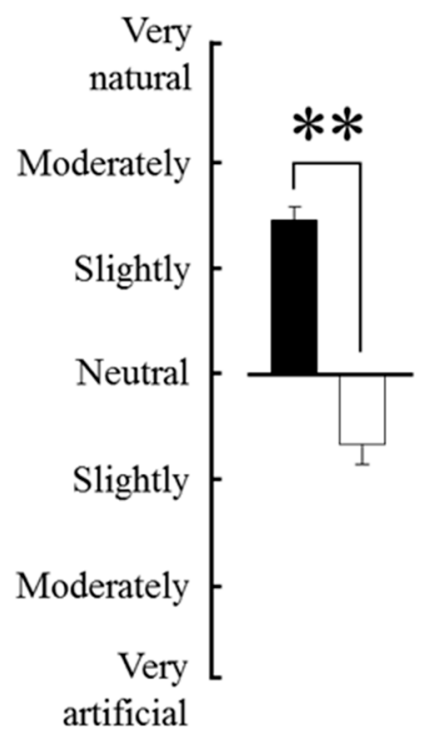

Figure 3. Comparison of the subjective scoring for comfortable, relaxed, and natural feelings between real and artificial flowers. $n=40$, mean \pm SE. $* * p<0.01$, determined by Wilcoxon signed-rank test (one-sided).

\section{Discussion}

We evaluated the physiological effects of visual stimulation with real and artificial pansies according to autonomic nerve activity. Compared with artificial flowers, real flowers significantly decreased sympathetic nerve activity. This result resembles that reported by a previous study on chrysanthemum transplantation for male university students with the Type A behavior pattern [27]. In contrast, some previous studies have reported increased parasympathetic nerve activity in addition to 
decreased sympathetic nerve activity, e.g., when viewing a forest environment in a sitting position [29,31,33,34] and following visual stimulation of high school students with fresh roses [41]. In addition, in some reports, only parasympathetic nerve activity increased, e.g., when viewing a forest environment in a sitting position [32] and following visual stimulation of office workers [40] or medical workers [42] with fresh roses. The cause of these differences remains unclear, and we intend to determine the cause(s) in future studies. With regard to the pulse rate, no significant difference was observed between the effect of real and artificial flowers. This result corresponds with that reported by previous studies, e.g., the chrysanthemum transplantation experiment [26] and the visual stimulation of high school students [41] or office workers [40] with fresh roses, which indicated no significant difference in pulse rate but a significant difference in HRV.

With regard to the psychological effects evaluated by the modified SD method, visual stimulation with real flowers resulted in "comfortable", "relaxed," and "natural" feelings. These results correspond with those of previous studies. In addition, few previous studies used the modified SD method on gardening activity, but chrysanthemum transplantation felt "comfortable", "soothed", and "natural" [41].

Considerable attention is being paid to the effect of forest environment on humans. In addition to psychological indices, comprehensive evaluation using physiological indices has been performed for forests, indicating that the forest environment has relaxation effects [28,29,32-36]. In contrast, with respect to gardening activity, many studies have reported the associated psychological effects [10-25]. However, knowledge regarding the physiological effects is insufficient. To elucidate the effects of gardening activity, comprehensive evaluation using both physiological and psychological indices is required. Hence, this study elucidated the relaxation effects of real flowers, used in a gardening activity, in terms of both physiological and psychological indices. The real pansies' odor was evaluated as "weak" in this study. However, a few previous studies have reported on the influence of odor on choice and preference even when the odor could not be detected at the olfactory level [58-60]. The potential influence of the weak odor of pansies on the physiological response or subjective evaluation remains to be clarified in a further study. In addition, the result may have been biased because of the knowledge of fresh flowers being "natural" and artificial flower being "unreal". In future studies, we aim to evaluate some aspects of nature connectedness and determine how these pre-determined ideas may influence the results.

In conclusion, compared with artificial pansies, visual stimulation with fresh pansies decreased sympathetic nerve activity and the subjects felt comfortable, relaxed, and natural. Visual stimulation with fresh pansies induced physiological and psychological relaxation effects on high school students.

This study has some limitations. First, high school students were the subjects in this study; studies with subjects from various ages and environments are required. Second, we used autonomic nerve activity as a physiological measurement. Other indices such as brain activity will be required from a perspective of systemic collaboration. Third, we focused on visual stimulation. However, we believe that the physiological effects of actually touching plants, such as transplantation, are important study themes.

We believe that this study provides important findings about the relationship between humans and natural environments. 


\section{Conclusions}

Compared with artificial pansies, visual stimulation with fresh pansies decreased sympathetic nerve activity and the subjects felt comfortable, relaxed, and natural. The findings indicate that visual stimulation with fresh pansies induced physiological and psychological relaxation effects on high school students.

\section{Acknowledgments}

This work was supported by a grant from the Policy Research Institute, Ministry of Agriculture, Forestry and Fisheries in Japan, "Extramural Research Program for Agricultural, Forestry and Fishery Policy Research". We really appreciate Hitoshi Watanabe, Associate Professor at the Centre for Environment, Health, and Field Sciences, Chiba University, who selected and prepared the pansies. We are grateful to Haruka Koizumi for her valuable contributions to data collection.

\section{Author Contributions}

Miho Igarashi contributed to data acquisition, statistical analysis, interpretation of the results, and manuscript preparation. Mariko Aga and Harumi Ikei contributed to data acquisition and statistical analysis. Takafumi Namekawa contributed to preparation of the experiment. Yoshifumi Miyazaki played an important role in this research, particularly in the study design, interpretation of data, and manuscript preparation. All authors contributed to manuscript preparation and are responsible for the final editing and approval of the manuscript.

\section{Conflicts of Interest}

The authors declare that they have no competing interests.

\section{References}

1. Brunet, M.; Guy, F.; Pilbeam, D.; Mackaye, H.T.; Likius, A.; Ahounta, D.; Beauvilain, A.; Blondel, C.; Bocherens, H.; Boisserie, J.R.; et al. A new hominid from the Upper Miocene of Chad, Central Africa. Nature 2002, 418, 145-151.

2. Bruxelles, L.; Clarke, R.J.; Maire, R.; Ortega, R.; Stratford, D. Stratigraphic analysis of the Sterkfontein StW 573 Australopithecus skeleton and implications for its age. J. Hum. Evol. 2014, 70, 36-48.

3. Kaplan, S. The restorative benefits of nature-Toward an integrative framework. J. Environ. Psychol. 1995, 15, 169-182.

4. Miyazaki, Y.; Park, B.J.; Lee, J. Nature therapy. In Designing Our Future:Local Perspectives on Bioproduction, Ecosystems and Humanity; Osaki, M., Braimoh, A.K., Nakagami, K., Eds.; United Nations: New York, NY, USA, 2011; pp. 407-412.

5. Ulrich, R.S.; Simons, R.F.; Losito, B.D.; Fiorito, E.; Miles, M.A.; Zelson, M. Stress recovery during exposure to natural and urban environments. J. Environ. Psychol. 1991, 11, 201-230.

6. Mitchell, R.; Popham, F. Effect of exposure to natural environment on health inequalities: An observational population study. Lancet 2008, 372, 1655-1660. 
7. Takano, T.; Nakamura, K.; Watanabe, M. Urban residential environments and senior citizens' longevity in megacity areas: The importance of walkable green spaces. J. Epidemiol. Commun. Health 2002, 56, 913-918.

8. Annerstedt, M.; Währborg, P. Nature-assisted therapy: Systematic review of controlled and observational studies. Scand. J. Public Health 2011, 39, 371-388.

9. Relf, D.; Dorn, S. Horticulture: Meeting the needs of special populations. HortTechnology 1995, 5, 94-103.

10. Barnicle, T.; Midden, K.S. The effects of a horticulture activity program on the psychological well-being of older people in a long-term care facility. HortTechnology 2003, 13, 81-85.

11. Gigliotti, C.M.; Jarrott, S.E. Effects of horticulture therapy on engagement and affect. Can. J. Aging 2005, 24, 367-377.

12. Gigliotti, C.M.; Jarrott, S.E.; Yorgason, J. Harvesting health effects of three types of horticultural therapy activities for persons with dementia. Dementia 2004, 3, 161-180.

13. Jarrott, S.E.; Gigliotti, C.M. Comparing responses to horticultural-based and traditional activities in dementia care programs. Am. J. Alzheimer. Dis. 2010, 25, 657-665.

14. Jarrott, S.E.; Kwack, H.R.; Relf, D. An observational assessment of a dementia-specific horticultural therapy program. HortTechnology 2002, 12, 403-410.

15. Lee, Y.; Kim, S. Effects of indoor gardening on sleep, agitation, and cognition in dementia patients-A pilot study. Int. J. Geriatr. Psychiatry 2008, 23, 485-489.

16. Tse, M.M.Y. Therapeutic effects of an indoor gardening programme for older people living in nursing homes. J. Clin. Nurs. 2010, 19, 949-958.

17. Gonzalez, M.T.; Hartig, T.; Patil, G.G.; Martinsen, E.W.; Kirkevold, M. Therapeutic horticulture in clinical depression: A prospective study of active components. J. Adv. Nurs. 2010, 66, 2002-2013.

18. Gonzalez, M.T.; Hartig, T.; Patil, G.G.; Martinsen, E.W.; Kirkevold, M. A prospective study of existential issues in therapeutic horticulture for clinical depression. Issues Ment. Health Nurs. 2011, $32,73-81$.

19. Richards, H.J.; Kafami, D.M. Impact of horticultural therapy on vulnerability and resistance to substance abuse among incarcerated offenders. J. Offender Rehabil. 1999, 29, 183-193.

20. Wichrowski, M.; Whiteson, J.; Haas, F.; Mola, A.; Rey, M.J. Effects of horticultural therapy on mood and heart rate in patients participating in an inpatient cardiopulmonary rehabilitation program. Cardiopulm. Rehabil. Prev. 2005, 25, 270-274.

21. Söderback, I.; Söderström, M.; Schälander, E. Horticultural therapy: The "healing garden" and gardening in rehabilitation measures at Danderyd hospital rehabilitation clinic. Sweden. Dev. Neurorehabil. 2004, 7, 245-260.

22. Armstrong, D. A survey of community gardens in upstate New York: Implications for health promotion and community development. Health Place 2000, 6, 319-327.

23. Kingsley, J.Y.; Townsend, M.; Henderson-Wilson, C. Cultivating health and wellbeing: Members' perceptions of the health benefits of a Port Melbourne community garden. Leisure Stud. 2009, 28, 207-219.

24. Wakefield, S.; Yeudall, F.; Taron, C.; Reynolds, J.; Skinner, A. Growing urban health: Community gardening in South-East Toronto. Health Promot. Int. 2007, 22, 92-101. 
25. Chawla, L.; Keena, K.; Pevec, I.; Stanley, E. Green schoolyards as havens from stress and resources for resilience in childhood and adolescence. Health Place 2014, 28, 1-13.

26. Van den Berg, A.E.; Custers, M.H.G. Gardening promotes neuroendocrine and affective restoration from stress. Health Psychol. 2011, 16, 3-11.

27. Lee, M.S.; Park, B.J.; Lee, J.; Park, K.T.; Ku, J.H.; Lee, J.W.; Oh, K.O.; Miyazaki, Y. Physiological relaxation induced by horticultural activity: Transplanting work using flowering plants. J. Physiol. Anthropol. 2013, 32, doi:10.1186/1880-6805-32-15.

28. Lee, J.; Park, B.J.; Tsunetsugu, Y.; Kagawa, T.; Miyazaki, Y. Restorative effects of viewing real forest landscapes, based on a comparison with urban landscapes. Scand. J. For. Res. 2009, 24, 227-234.

29. Lee, J.; Park, B.J.; Tsunetsugu, Y.; Ohira, T.; Kagawa, T.; Miyazaki, Y. Effect of forest bathing on physiological and psychological responses in young Japanese male subjects. Public Health 2011, 125, 93-100.

30. Park, B.J.; Furuya, K.; Kasetani, T.; Takayama, N.; Kagawa, T.; Miyazaki, Y. Relationship between psychological responses and physical environments in forest settings. Landscape Urban Plan. 2011, 102, 24-32.

31. Park, B.J.; Tsunetsugu, Y.; Lee, J.; Miyazaki, Y. Effect of the forest environment on physiological relaxation-the results of field tests at 35 sites throughout Japan. In Forest Medicine; Li, Q., Ed.; Nova Science Publishers: New York, NY, USA, 2011; pp. 55-65.

32. Park, B.J.; Tsunetsugu, Y.; Ishii, H.; Furuhashi, S.; Hirano, H.; Kagawa, T.; Miyazaki, Y. Physiological effects of Shinrin-yoku (taking in the atmosphere of the forest) in a mixed forest in Shinano Town, Japan. Scand. J. For. Res. 2008, 23, 278-283.

33. Park, B.J.; Tsunetsugu, Y.; Kasetani, T.; Morikawa, T.; Kagawa, T.; Miyazaki, Y. Physiological effects of forest recreation in a young conifer forest in Hinokage Town, Japan. Silva Fenn. 2009, 43, 291-301.

34. Tsunetsugu, Y.; Lee, J.; Park, B.J.; Tyrvainen, L.; Kagawa, T.; Miyazaki, Y. Physiological and psychological effects of viewing urban forest landscapes assessed by multiple measurements. Landsc. Urban Plan. 2013, 113, 90-93.

35. Tsunetsugu, Y.; Park, B.J.; Miyazaki, Y. Trends in research related to "Shinrin-yoku" (taking in the forest atmosphere or forest bathing) in Japan. Environ. Health Prev. Med. 2010, 15, 27-37.

36. Tsunetsugu, Y.; Park, B.J.; Miyazaki, Y. Physiological effects of visual, olfactory, auditory, and tactile factors in the forest environment. In Forest Medicine; Li, Q., Ed.; Nova Science Publishers: New York, NY, USA, 2011; pp. 169-181.

37. Song, C.; Joung, D.; Ikei, H.; Igarashi, M.; Aga, M.; Park, B.J.; Miwa, M.; Takagaki, M.; Miyazaki, Y. Physiological and psychological effects of walking on young males in urban parks in winter. J. Physiol. Anthropol. 2013, 32, doi:10.1186/1880-6805-32-18.

38. Song, C.; Ikei, H.; Igarashi, M.; Miwa, M.; Takagaki, M.; Miyazaki, Y. Physiological and psychological responses of young males during spring-time walks in urban parks. J. Physiol. Anthropol. 2014, 33, doi:10.1186/1880-6805-33-8.

39. Matsunaga, K.; Park, B.J.; Kobayashi, H.; Miyazaki, Y. Physiologically relaxing effect of a hospital rooftop forest on older women requiring care. J. Am. Geriatr. Soc. 2011, 59, 2162-2163. 
40. Ikei, H.; Komatsu, M.; Song, C.; Himoro, E.; Miyazaki, Y. The physiological and psychological relaxing effects of viewing rose flowers in office workers. J. Physiol. Anthropol. 2014, 33, doi:10.1186/1880-6805-33-6.

41. Ikei, H.; Lee, J.; Song, C.; Komatsu, M.; Himoro, E.; Miyazaki, Y. Physiological relaxation of viewing rose flowers in high school students. Jpn. J. Physiol. Anthropol. 2013, 18, 97-103.

42. Komatsu, M.; Matsunaga, K.; Lee, J.; Ikei, H.; Song, C.; Himoro, E.; Miyazaki, Y. The physiological and psychological relaxing effects of viewing rose flowers in medical staff. Jpn. J. Physiol. Anthropol. 2013, 18, 1-7.

43. Igarashi, M.; Song, C.; Ikei, H.; Miyazaki, Y. Effect of stimulation by foliage plant display images on prefrontal cortex activity: A comparison with stimulation using actual foliage plants. J. Neuroimaging 2014, 25, 127-130.

44. Ikei, H.; Song, C.; Igarashi, M.; Namekawa, T.; Miyazaki, Y. Physiological and psychological relaxing effects of visual stimulation with foliage plants in high school students. Adv. Hortic. Sci. 2014, 28, 111-116.

45. Igarashi, M.; Song, C.; Ikei, H.; Ohira, T.; Miyazaki, Y. Effect of olfactory stimulation by fresh rose flowers on autonomic nervous activity. J. Altern. Complement. Med. 2014, 20, 727-731.

46. Igarashi, M.; Song, C.; Ikei, H.; Miyazaki, Y. Effects of olfactory stimulation with perilla essential oil on prefrontal cortex activity. J. Altern. Complement. Med. 2014, 20, 545-549.

47. Igarashi, M.; Ikei, H.; Song, C.; Miyazaki, Y. Effects of olfactory stimulation with rose and orange oil on prefrontal cortex activity. Complement. Ther. Med. 2014, 22, 1027-1031.

48. Joung, D.; Song, C.; Ikei, H.; Okuda, M.; Igarashi, M.; Koizumi, H.; Park, B.J.; Yamaguchi, T.; Takagaki, M.; Miyazaki, Y. Physiological and psychological effects of olfactory stimulation with D-Limonene. Adv. Hortic. Sci. 2014, 28, 90-94.

49. Park, B.J.; Ono, K.; Yoshinami, Y.; Miyazaki, Y. Physiological effects of orange essential oil inhalation in humans. Adv. Hortic. Sci. (In press).

50. Cabinet Office Government of Japan White Paper on Children and Young People 2013 (Summary). Available online: http://www8.cao.go.jp/youth/english/whitepaper/2013/pdf/part1.pdf(accessed on 26 January 2015).

51. Twenge, J.M.; Gentile, B.; DeWall, C.N.; Ma, D.; Lacefield, K.; Schurtz, D.R. Birth cohort increases in psychopathology among young Americans, 1938-2007: A cross-temporal meta-analysis of the MMPI. Clin. Psychol. Rev. 2010, 30, 145-154.

52. Collishaw, S.; Maughan, B.; Natarajan, L.; Pickles, A. Trends in adolescent emotional problems in England: A comparison of two national cohorts twenty years apart. J. Child Psychol. Psychiatry 2010, 51, 885-894.

53. Takada, H.; Okino, K.; Niwa, Y. An evaluation method for heart rate variability, by using acceleration plethysmography. Health Eval. Promot. 2004, 31, 547-551.

54. Kanaya, N.; Hirata, N.; Kurosawa, S.; Nakayama, M.; Namiki, A. Differential effects of propofol and sevoflurane on heart rate variability. Anesthesiology 2003, 98, 34-40. 
55. Camm, A.J.; Malik, M.; Bigger, J.T.; Breithardt, G.; Cerutti, S.; Cohen, R.J.; Coumel, P.; Fallen, E.L.; Kennedy, H.L.; Kleiger, R.E.; et al. Heart rate variability: Standards of measurement, physiological interpretation and clinical use. Task force of the European society of cardiology and the North American society of pacing and electrophysiology. Circulation 1996, 93, 1043-1065.

56. Pagani, M.; Lombardi, F.; Guzzetti, S.; Rimoldi, O.; Furlan, R.; Pizzinelli, P.; Sandrone, G.; Malfatto, G.; Dell'Orto, S.; Piccaluga, E. Power spectral analysis of heart rate and arterial pressure variabilities as a marker of sympatho-vagal interaction in man and conscious dog. Circ. Res. 1986, 59, 178-193.

57. Osgood, C.E.; Suci, G.J.; Tannenbaum, P. The Measurement of Meaning; University of Illinois Press: Chicago, IL, USA, 1957.

58. Gaillet-Torrent, M.; Sulmont-Rossé, C.; Issanchou, S.; Chabanet, C.; Chambaron, S. Impact of a non-attentively perceived odour on subsequent food. Appetite 2014, 76, 17-22.

59. Yamada, Y.; Sasaki, K.; Kunieda, S.; Wada, Y. Scents boost preference for novel fruits. Appetite 2014, 81, 102-107.

60. Li, W.; Moallem, I.; Natarajan, L.; Paller, K.A.; Gottfried, J.A. Subliminal smells can guide social preferences. Psychol. Sci. 2007, 18, 1044-1049.

(C) 2015 by the authors; licensee MDPI, Basel, Switzerland. This article is an open access article distributed under the terms and conditions of the Creative Commons Attribution license (http://creativecommons.org/licenses/by/4.0/). 